\title{
Basset, Úrsula
}

\section{Régimen patrimonial del matrimonio}

\section{Facultad de Derecho}

Este documento está disponible en la Biblioteca Digital de la Universidad Católica Argentina, repositorio institucional desarrollado por la Biblioteca Central "San Benito Abad". Su objetivo es difundir y preservar la producción intelectual de la Institución.

La Biblioteca posee la autorización del autor y de la editorial para su divulgación en línea.

Cómo citar el documento:

Basset, U. (2012). Régimen patrimonial del matrimonio [en línea]. En Análisis del nuevo Código Civil y Comercial 2012. Buenos Aires : El Derecho. Disponible en: http://bibliotecadigital.uca.edu.ar/repositorio/contribuciones/regimenpatrimonial-matrimonio-basset.pdf [Fecha de consulta:..............]

(Se recomienda indicar al finalizar la cita la fecha de consulta. Ej: [Fecha de consulta: 19 de agosto de 2010]). 


\section{RÉGIMEN PATRIMONIAL DEL MATRIMONIO}

\section{Úrsula C. Basset}

El régimen de bienes ofrece varias novedades. No obstante, en líneas generales sigue los proyectos de 1993 y 1998, según las indicaciones de la Comisión de Reformas. Desde luego que, dado que las secciones del Proyecto que han regulado los efectos personales se han apartado en forma significativa de los Proyectos de 1993 y 1998, y aun, en muchos casos, de la apreciación de la doctrina mayoritaria y del entendimiento del hombre común en relación a las instituciones reguladas. En este estado de cosas, no cabe duda de que hay un evidente desajuste entre la regulación libertaria de los efectos personales del matrimonio y la familia; y la regulación más conservadora de los efectos económicos del matrimonio. Siempre se ha sostenido que la regulación de los efectos del matrimonio depende de una idea de matrimonio que obra como su fundamento y causa teórica adecuada. Dado que en las diversas subcomisiones se trabajó en forma separada, la regulación del matrimonio y sus consecuencias personales no responde en absoluto al perfil de matrimonio que subyace a la regulación de los efectos económicos. El desajuste es evidente.

\section{a) Consideraciones generales}

Una regulación totalmente incoherente con los efectos personales del matrimonio. Mientras que en el matrimonio hay más libertad entre los cónyuges entre sí que si se tratara de un contrato o aun de una unión convivencial, parece totalmente contrario al buen sentido que una institución sin relevancia para el orden público proyecte tan gran cantidad de efectos económicos y sucesorios. Lo coherente sería eliminar toda regulación, dando total libertad a los cónyuges y estableciendo un sistema de separación cuyo único gravamen a las libertades individuales de disposición estuviera dado por la protección de los derechos de los niños.

Se incorporan las convenciones matrimoniales, pero de manera muy limitada y restringiendo la libertad de los cónyuges en materia de opciones y en cuanto a la facultad de los cónyuges de cambiar de régimen. Como parte de las nuevas incorporaciones al régimen de bienes, aparecen las convenciones matrimoniales. Como es sabido, Vélez Sarsfield las había rechazado por ser ajenas a nuestras costumbres y por considerarlas indecorosas (consideraba indecoroso que quienes compartirían la totalidad de sus vidas discutieran sobre la minucia del dinero antes de ingresar en la relación matrimonial). En todos los proyectos de reforma hasta 1993 se rechazaba la posibilidad de la elegibilidad de regímenes. Por otra parte, el mundo advierte que los regímenes de bienes separatistas en raras circunstancias son ventajosos. Las más de las veces conspiran contra los derechos de la mujer. Así las cosas, siendo de nuestra parte contrarios a la elegibilidad de los regímenes matrimoniales, consideramos que la regulación prevista en el Proyecto tenía la gran virtud de la mesura. No obstante, al ver el cuadro completo de lo regulado, no puede menos que expresarse la incoherencia entre la 
cautela en regular los efectos económicos y el espíritu de neta innovación con que se regularon los efectos personales.

Como ya se ha dicho, la coherencia hubiera ameritado total libertad, ningún régimen económico, resguardo de derechos de los niños en bienes y necesidades que los conciernan y resguardo de derechos de terceros respecto de aquellos bienes.

Se perdió la posibilidad de regular conjuntamente alimentos, prestación compensatoria, deber de contribución y liquidación de la sociedad conyugal. Hubiera sido una extraordinaria oportunidad para trabajar conjuntamente entre las diversas secciones del Código Civil, evitando rubros superpuestos en materia de las proyecciones económicas del matrimonio. En su lugar, la modalidad de trabajo en compartimientos estancos y la falta de posibilidad de revisión e integración de todas las secciones terminó por oscurecer la posibilidad de coherencia y coordinación que todos estos aspectos hubieran requerido.

\section{b) Convenciones matrimoniales}

Se incorporan las convenciones matrimoniales prenupciales y posnupciales. Sin embargo, se incorporan solo dos alternativas: comunidad y separación. La subcomisión había regulado además el régimen de participación. Creemos que debió haberse incorporado además el régimen de comunidad plena, que podría beneficiar a personas que contraen nupcias teniendo una edad avanzada y prefieren confundir sus patrimonios a deferirlos por sucesión.

\section{c) Disposiciones comunes a todos los regímenes}

Existen disposiciones comunes a todos los regímenes. Ellas se refieren al deber de contribución a su propio sostenimiento, al del hogar y de los hijos comunes en proporción a sus recursos. El Art. 456 (versión del 12.04.2012) dice que en todos los casos se requiere el asentimiento del cónyuge sobre los derechos de la vivienda familiar y los muebles indispensables de esta. La vivienda no puede ser ejecutada por deudas contraídas por un cónyuge sin el asentimiento del otro. El Art. 459 prevé el mandato entre cónyuges. El Art. 461 prevé responsabilidad solidaria por las obligaciones contraídas por uno de ellos para solventar las necesidades ordinarias del hogar o el sostenimiento de los hijos comunes.

\section{d) Régimen de comunidad o primario}

El régimen de comunidad es régimen primario y conserva a grandes rasgos su fisonomía previamente conocida. Consistente con la idea de no innovar demasiado, para que la sección de régimen de bienes respondiera a las expectativas jurídicas de la comunidad, el régimen de comunidad ha seguido los trazos básicos ya conocidos por todos. Por esa misma razón, el régimen de comunidad permanece como régimen primario, vale decir, el que regirá si ninguno de los cónyuges hace ninguna opción por el de separación (única otra alternativa posible, cfr. Art. 464 de la versión del 12.04.2012). Se trata de un régimen de comunidad de ganancias.

\section{Reglas de calificación de bienes}

En cuanto a la calificación de bienes se clarificaron algunos supuestos. Lamentablemente se excluyó la regulación prevista en materia de acciones sociales, que hubiera evitado conflictos en torno a su calificación. En cuanto a la calificación de bienes a grandes rasgos se trata de lo mismo que ya se 
conocía. Se incorporan supuestos anteriormente considerados dudosos tales como las ropas y objetos de uso personal, la cuestión relativa a los bienes necesarios para el trabajo o la profesión, el derecho a la jubilación o pensión, el derecho de alimentos y otros semejantes. Sigue rigiendo la presunción de ganancialidad.

En cuanto a los bienes propios se incorpora el asunto de las crías de ganado, y se aclara que se excluyen las indemnizaciones.

\section{Negativo. La ausencia de reglas en torno a la calificación de participaciones societarias}

En cuanto a las participaciones societarias: Seguimos pensando que las participaciones societarias siguen por subrogación real al dinero con el que fueron adquiridas. La distribución de ganancias, en acciones o en dinero tiene naturaleza ganancial. En cambio, las ganancias llevadas a reserva, toda vez que no son propiedad de los cónyuges sino de la sociedad, no son objeto de calificación alguna (no son ni propias ni gananciales, simplemente porque no son de los cónyuges, sino de la sociedad). Queda a salvo la acción de fraude, si hubiera motivos para pensar que por la integración de la Asamblea que llevó a reservas las ganancias, hubo fraude a los derechos del otro cónyuge.

\section{Presunción de ganancialidad de carácter probatorio}

Sigue rigiendo la presunción de ganancialidad, pero queda formulada como una regla de prueba. Así aparece en el nuevo Art. 466 del Proyecto (versión del 12.04.2012).

\section{Régimen de deudas}

El régimen de deudas en la comunidad se ha mejorado mucho, toda vez que se ha dado respuesta a diversas inquietudes doctrinales. Rige el principio de separación de deudas, salvo en el caso de gastos de conservación y reparación de los gananciales (Art. 467, de la versión del 12.04.2012) y por los gastos de conservación y reparación de los bienes gananciales responde también el cónyuge que no contrajo la deuda.

\section{Régimen de gestión y disposición}

La gestión de bienes se rige por el principio de libre administración y disposición, salvo los bienes pertenecientes al hogar conyugal y los bienes gananciales registrables. Las acciones nominativas no endosables y las no cartulares con excepción de las autorizadas para la oferta pública. Los bienes adquiridos conjuntamente responden conjuntamente a ambos.

\section{Extinción de la comunidad}

La comunidad se extingue por muerte, anulación de matrimonio, divorcio, separación judicial de bienes y modificación del régimen matrimonial convenido. La separación de bienes (se mantiene el procedimiento) procede ante la mala administración de uno de los cónyuges acarrea al otro el peligro de perder su eventual derecho sobre los gananciales, si se declara el concurso preventivo o la quiebra del otro cónyuge, si los cónyuges están separados de hecho sin voluntad de unirse, si por incapacidad o excusa de uno de los cónyuges se designa curador del otro a un tercero. 
Otra introducción interesante es la precisión en torno al momento en que se extingue la comunidad, la cual recoge principios jurisprudenciales y doctrinales y se encuentra comprendida en el Art. 480.

\section{Se regula finalmente la indivisión poscomunitaria}

Se introduce la regulación de la indivisión poscomunitaria, tantas veces reclamada por la doctrina. En la sección 6ta. Se introduce su regulación. Se aplican las reglas de la indivisión hereditaria si la causa de disolución es la muerte de uno de los cónyuges. Si se extingue en vida, se aplican las reglas propuestas en la sección de régimen patrimonial del matrimonio. La regla es el acuerdo de los cónyuges sobre cómo se ejercerá la administración. A falta de acuerdo se prevé un régimen supletorio, que es el propio de la vigencia de la comunidad (administración separada, salvo las excepciones explicitadas más arriba). Sin embargo, se agrega la carga de un deber de información razonablemente anticipado, si se otorgarán actos que excedan la administración ordinaria de bienes indivisos. El otro cónyuge podrá deducir oposición (Art. 482, versión del 12.04.2012). Se establecen reglas para el uso de los bienes indivisos, por los cuales cualquiera puede usarlos de común acuerdo y a falta de acuerdo, el juez puede decidir quién los use. El uso y goce que exceda lo convenido puede dar derecho a indemnizar solo a partir de la oposición fehaciente. Los frutos y rentas acrecen la indivisión y el copropietario debe rendición de cuentas, así como quien tiene uso y goce exclusivo puede deber compensación a la masa desde que es solicitada por el otro. El pasivo también es regulado. Se rige por las reglas del régimen de deudas durante la vigencia de la comunidad, sin perjuicio del derecho de los terceros acreedores de subrogarse en los derechos del deudor para solicitar la partición de la masa común.

\section{Recompensas}

Respecto de la liquidación de la comunidad, por primera vez se regulan las recompensas. En el Art. 488 (versión del 12.04.2012) se introduce la regulación de las recompensas. Se detallan los casos de recompensas (Art. 491) por medio de una regla general: la comunidad debe recompensa al cónyuge si esta se ha beneficiado en detrimento del patrimonio propio y viceversa. La clave de apertura es el beneficio a expensas de otro, por lo cual queda claro que el concepto teórico subyacente es el del enriquecimiento sin causa.

Se establecen en ese artículo además una presunción y una solución relativa a las sociedades y a los fondos de comercio. La presunción responde a un lugar común de la doctrina: si durante la comunidad uno de los cónyuges a enajenado bienes propios a título oneroso sin reinvertir su precio se presume que lo percibido a beneficiado a la comunidad. Esta presunción ya existía como construcción jurisprudencial y solo se volcado en la legislación lo que la sociedad aplicaba.

\section{Un aerolito del régimen de calificación de bienes en las recompensas. Un error que conven- dría rectificar a tiempo}

En cambio, en el último párrafo del Art. 491 se introduce una causa de recompensas que aparece como un aerolito relativo a las reglas de calificación, sin encontrar en ellas adecuada coherencia con ellas ni con la regulación de la personalidad jurídica de las sociedades. En efecto, habíamos resaltado la falta de una regulación en torno a una cuestión tan problemática como lo son las acciones y participaciones sociales. Era urgente despejar el carácter propio o ganancial de las mismas y en el capítulo de calificación de bienes nada se dice al respecto. Pues bien, en la sección de casos de recompensas, sin haberse pronunciado respecto de la calificación de las participaciones sociales (y peor aún: so- 
bre la capitalización de utilidades), el codificador (el texto no proviene de la subcomisión y fue un agregado ulterior) establece un derecho a recompensas por el aumento de valor de una acción social derivada de las utilidades. Ahora bien, existen varios problemas en torno a esta "recompensa", que en realidad es una calificación de bienes velada. La primera es que establece la regla de que el mayor valor de los bienes propios, es ganancial. Esa regla es contraria a la opinión doctrinal mayoritaria.

En segundo lugar, establece una contradicción a la regla general enunciada en el primer párrafo en el supuesto de recompensas: si antes se había dicho que tiene que haber un beneficio de uno de los cónyuges en detrimento de la comunidad para que nazcan las recompensas, ahora se dice que si un cónyuge se enriquece sin detrimento de la comunidad, también habrá recompensas -sin justificar la motivación del cambio de criterio-.

En tercer lugar, la regla es de muy difícil prueba y hasta cierto punto antijurídica. Nos explicamos. Es de difícil prueba, porque el aumento de valor de las participaciones sociales responderá con frecuencia a factores complejos cuya interrelación haga probablemente imposible aislar un fenómeno como causa exclusiva (en el caso, la capitalización de utilidades). Ahora bien, en caso de que fuera posible aislar un solo fenómeno como causalidad adecuada para el aumento de valor de las participaciones sociales, el otro cónyuge pretendería recompensa porque un giro del patrimonio de la sociedad. Es decir, que la causa de la recompensa sería el patrimonio de otra persona jurídica independiente de los cónyuges. Sería implementar una suerte de "disregard" de la personalidad social a los efectos económicos del matrimonio, lo que es de juridicidad, por lo menos, dudosa. Más lógico sería evidenciar el recurso al fraude, para el cónyuge que percibe que las utilidades se capitalizan para evitar una distribución que podría enriquecer más la comunidad.

La regulación continúa introduciendo criterios para discriminar el monto de las recompensas (siguiendo las reglas de 1993: es igual al menor de los valores que representan la erogación y el provecho subsistente para el cónyuge o para la comunidad, al día de su extinción, apreciados en valores constantes; si no hubiera beneficio, se toma el valor de la erogación); la valuación de las recompensas (los bienes se valúan según su estado al día de la disolución del régimen y según su valor al tiempo de la liquidación); y de liquidación, en el que se prevé que si la masa ganancial fuera insuficiente, el cónyuge acreedor tendrá un crédito contra el otro. Estas últimas reglas son tan discutibles como cualquier otro criterio posible. La inestabilidad de la economía y la prolongación de los pleitos complejos en los que existen muchos bienes, indudablemente conspira contra soluciones más perfectas. Será tarea del juez tratar de corregir con estas reglas generales la infinita variedad de casos concretos.

\section{Cargas de la comunidad}

Las cargas de la comunidad consisten en las obligaciones contraídas durante la comunidad, el sostenimiento del hogar, de los hijos comunes y de los que cada uno tenga, más los alimentos que cada uno esté obligado a dar, las donaciones de los bienes gananciales hechas a los hijos comunes y aun la de los propios si están destinados a su establecimiento y colocación y los gastos de conservación y reparación de los bienes propios y gananciales. Es de destacar la ampliación de las cargas a los hijos no comunes, sin aclarar si son mayores o menores de edad o si conviven con el matrimonio.

\section{Partición}

La sección 8va. se refiere a la partición de la comunidad y la regula. El derecho a pedirla puede ejercerse en todo tiempo. La masa partible se integra con la suma de los activos gananciales líquidos de uno y otro cónyuge. Se establece el principio de partición por mitades sin consideración al monto de los bienes propios ni a la contribución de cada uno a la masa ganancial. Los cónyuges pueden derogar la regla de la partición por mitades por vía de convenio. Una novedad es el derecho a peticionar una atribución preferencial de los bienes amparados por las reglas de la propiedad inte- 
lectual o artística, del establecimiento comercial, industrial o agropecuario adquirido por uno de los cónyuges o que constituya una unidad económico y de la vivienda por el ocupada al tiempo de la extinción de la comunidad, aunque exceda su parte y deba pagar la diferencia al otro cónyuge. Para la partición, en cuanto a la forma, rigen las reglas de la partición de herencia. Los gastos son a cargo de los cónyuges a prorrata de su participación en los bienes. Después de la partición cada uno de los cónyuges responde frente a sus acreedores con los bienes propios o gananciales que le hubieran sido atribuidos.

\section{e) Régimen de separación de bienes}

El régimen de separación de bienes se rige por la libertad de gestión, pero está gravado por un régimen general de cargas imperativas en relación al matrimonio. Si bien cada uno responde por sus deudas y cada uno administra y dispone de sus bienes (Art. 505, versión del 12.04.2012) es también cierto que el régimen general de responsabilidad por deudas y el deber de contribución rigen aun en el régimen de bienes. La división de condominio de los cónyuges por uno de ellos o por un tercero puede ser negada si afecta el interés familiar. La separación de bienes cesa por la modificación del régimen convenido y por la disolución del matrimonio.

\section{f) Balance final de régimen de bienes}

El balance final del régimen de bienes presenta una fisonomía de matrimonio que es bastante más coherente con la expectativa del hombre común y las costumbres jurídicas nacionales que la reforma en torno a los efectos personales. De nuestra parte, consideramos que el régimen que más se ajusta a la esencia del matrimonio y a la plena protección de los derechos de la mujer y la familia es un régimen único de comunidad (en cualquiera de sus variantes).

De todas formas, así como está planteado el régimen de efectos personales, dado que el matrimonio pierde totalmente su esencia, quedando más bien reducido a un trámite altamente burocratizado sin contenido alguno, sin que la familia tenga interés público; no se entiende bien cuál es el fundamento constitucional para limitar las libertades en torno al derecho de propiedad de los contrayentes, estableciendo un régimen patrimonial restrictivo. Creemos que al matrimonio regulado (que poco tiene de interés público) le cabe mejor la ausencia total de régimen.

Desde luego que entre el régimen regulado y el matrimonio como institución social percibida por la gente hay una intersección (bien señalada por el teórico español Carlos Martínez de Aguirre): el matrimonio social. El matrimonio social no es el matrimonio jurídico, y las expectativas de la gente respecto del matrimonio no es lo que queda plasmado en la regulación del proyecto. En consecuencia, para proteger a aquellos que por desconocimiento de la ley (cosa muy frecuente cuando la ley se aparta mucho de las expectativas sociales) sigan contrayendo el matrimonio de acuerdo a lo que ellos razonablemente creen que el matrimonio es (con deberes de fidelidad, asistencia y cohabitación, por ejemplo), sería razonable dejar establecido un régimen primario que responda a la esencia de esa idea social de matrimonio: el régimen de comunidad. 